\title{
PERANCANGAN ZETA CONVERTER PADA PELACAKAN TITIK DAYA MAKSIMUM PHOTOVOLTAIC MENGGUNAKAN ALGORITMA MODIFIKASI HILL CLIMBING
}

\author{
Irwan Mahmudi ${ }^{1)}$, Jumiyatun ${ }^{2)}$, Baso Mukhlis ${ }^{3)}$, Lukman $^{4)}$ \\ ${ }^{1,2,3)}$ Dosen Jurusan Teknik Elektro Universitas Tadulako \\ ${ }^{4}$ Mahasiswa Teknik Elektro Universitas Tadulako \\ E-mail : irwan.mahmudi@untad.ac.id, jum.elektro@gmail.com, lukman230796@gmail.com
}

\begin{abstract}
Abstrak
Electrical energy is a primary need at this time, which almost all human activities require electricity. The electrical energy we use today is a conversion from other energy, partly derived from fossil energy, which is energy that cannot be renewed and will run out if it is continuously explored and exploited. Solar energy is a renewable energy source that has the potential to be converted to electrical energy using solar panels or socalled photovoltaics.

Photovoltaic has a drawback in its use, namely the output value is very dependent on environmental conditions. To maximize the power efficiency between the photovoltaic output and the power to be used by the load, a method is needed, namely Maximum Power Point Tracking (MPPT). In the application of this MPPT DC-DC Zeta converter is used with a hill climbing algorithm to achieve the value of the output voltage and current at maximum power. With this method, it is expected that MPPT control is reliable and easy to apply.

In this study, the type of photovoltaic module used is the $60 \mathrm{Wp}$ monocrystalline type with sampling data once an hour from 09.00 - 17.00 WITA, the tracking speed data obtained by the modified hill climbing algorithm is 0.142 seconds on average with an average efficiency of $99.969 \%$.
\end{abstract}

Keywords: Photovoltaic, MPPT, Modified Hill Climbing Algorithm, Zeta Converter

\section{PENDAHULUAN}

Photovoltaic adalah peralatan yang mengubah cahaya menjadi aliran listrik menggunakan efek photovoltaic. Photovoltaic tidak membutuhkan bahan bakar minyak, tidak menimbulkan polusi dan ramah lingkungan serta sangat baik digunakan di daerah tropis seperti di Indonesia. [7] Namun dibalik kelebihan tersebut photovoltaic memiliki kekurangan dalam penggunaannya yaitu nilai keluaran yang sangat bergantung pada keadaan lingkungan (intensitas matahari dan suhu). Hal tersebut mengakibatkan daya yang dihasilkan oleh photovoltaic tidak dapat terpakai sepenuhnya oleh beban.

Untuk memaksimalkan effisiensi daya antara output photovoltaic dan daya yang akan digunakan beban maka diperlukan sebuah metode yaitu Pelacakan Titik Daya Maksimum atau biasa biasa disebut Maximum Power Point Tracker (MPPT). [1] MPPT adalah suatu metode untuk menjejak (track) titik kerja sebuah sumber energi agar menghasilkan daya maksimum. Ketika kondisi beban atau atmosfer yang berbeda maka daya output maksimum sel PV terjadi pada nilai arus dan tegangan tentu berbeda. Dengan kendali MPPT diharapkan terjadi konversi energi maksimal pada berbagai kondisi. 
Metode MPPT dapat dilakukan dengan berbagai metode antara lain fuzzy logic control (FLC), jaringan syaraf tiruan, dan berbagai macam algoritma lainnya. Tiap metode pasti memiliki kelebihan dan kekurangannya masing-masing antara lain jumlah iterasi yang banyak dan sulit untuk diimplementasikan. Salah satu metode yang cukup handal dan mudah di implementasikan adalah algoritma hill climbing. Dengan metode ini diharapkan kendali MPPT yang handal serta mudah diterapkan. Dalam penerapan MPPT membutuhkan konverter DC-DC untuk mencapai nilai tegangan dan arus output yang diinginkan, dan pada penelitian ini penulis akan menggunakan Zeta Converter dan algoritma modified hill climbing sebagai metode MPPT-nya. [3]

\section{METODE PENELITIAN}

\subsection{Rancangan Penelitian}

Gambar 3.1. penulis buat untuk menggambarkan dari diagram blok system dari penelitian ini. Dimana MPPT controller memegang kendali atas konverter dengan mengubah nilai duty cyclye secara bertahap. [4] Perubahan nilai duty cycle dilakukan untuk mendapatkan nilai daya maksimum, dengan data referensi nilai arus input $\left(\mathrm{I}_{\text {in }}\right)$ dan tengan input $\left(\mathrm{V}_{\text {in }}\right)$ Zeta converter yang merupakan nilai output $P V$. [2]

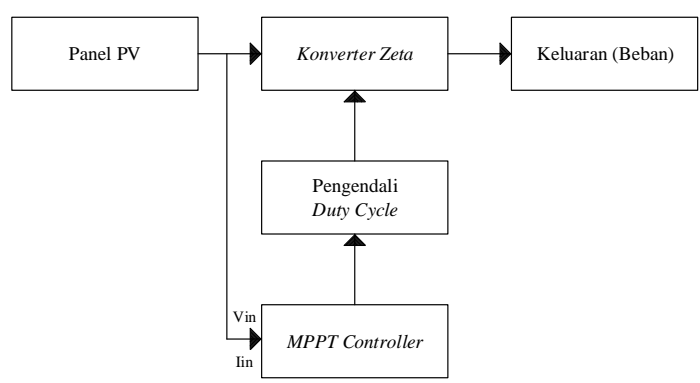

Gambar 1. Diagram blok rangkaian

\subsection{Cara Penelitian}

Adapun bentuk rancangan dari penelitian ini adalah sebagai berikut :

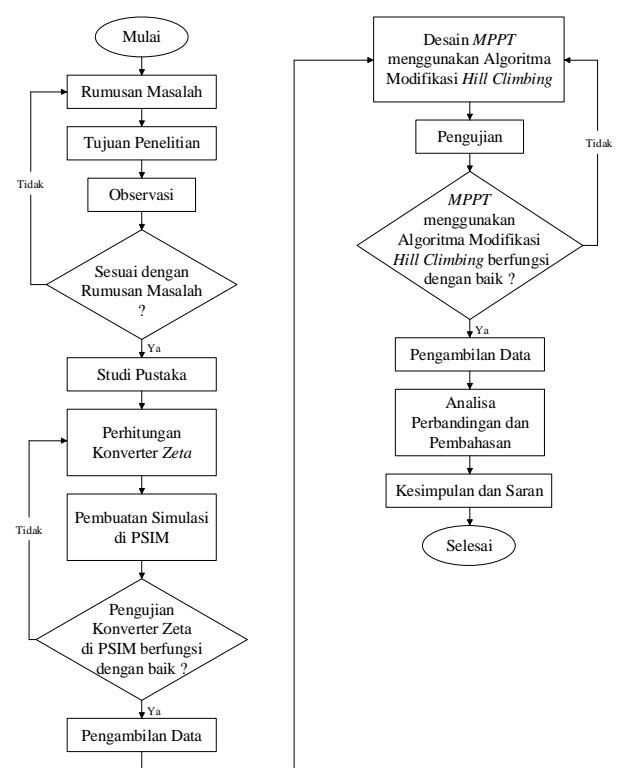

Gambar 2. Flowchart cara penelitian

Cara kerja sistem yang direncanakan ini adalah sebagai berikut:

a. Keluaran tegangan dan arus dari $P V$ akan masuk pada Zeta Converter.

b. Keluaran tegangan dan arus dari $P V$ akan masuk pada controller MPPT (dalam bentuk data yang diambil dari voltage sensor dan current sensor).

c. Kontroler MPPT menggunakan metode Algoritma Modifikasi Hill Climbing telah mencari Vmpp pada $P V$.

d. Keluaran dari kontroler MPPT (Vmpp) masuk pada pengendali duty cycle yang akan memberikan umpan balik ke Zeta Converter.

e. Umpan balik yang diterima oleh Zeta Converter akan mengeluarkan Vmpp dari $P V$ sehingga daya maksimal dari $P V$ dapat dicapai.

\section{HASIL DAN PEMBAHASAN}

\subsection{Data Panel Surya}




\section{Jurnal Ilmiah Foristek

Tabel 1. Spesifikasi panel surya monokristalin $60 \mathrm{Wp}$

\begin{tabular}{|l|c|}
\hline Daya Maksimum $\left(\mathrm{P}_{\text {Max }}\right)$ & $60 \mathrm{Wp}$ \\
\hline Tegangan Daya Maksimum $\left(\mathrm{V}_{\mathrm{MP}}\right)$ & $23.73 \mathrm{~V}$ \\
\hline Arus Daya Maksimum $\left(\mathrm{I}_{\mathrm{MP}}\right)$ & $2.55 \mathrm{~A}$ \\
\hline Tegangan Hubung Buka $\left(\mathrm{V}_{\mathrm{OC}}\right)$ & $27.87 \mathrm{~V}$ \\
\hline Arus Hubung Singkat $\left(\mathrm{I}_{\mathrm{SC}}\right)$ & $2.78 \mathrm{~A}$ \\
\hline
\end{tabular}

Tabel 1. adalah data nameplate $P V$ monokristalin yang digunakan pada penelitian ini, data tersebut berguna sebagai dasar dalam pemodelan pv yang akan disimulasikan. Dalam memodelkan $P V$ juga dibutuhkan data pengukuran real untuk dibandingkan hasilnya dengan data simulasi. Tabel 2. memperlihatkan data hasil pengukuran pada $P V$. [6]

Tabel 1. Data Hasil Pengukuran Photovoltaic Monocrystalline $60 \mathrm{Wp}$

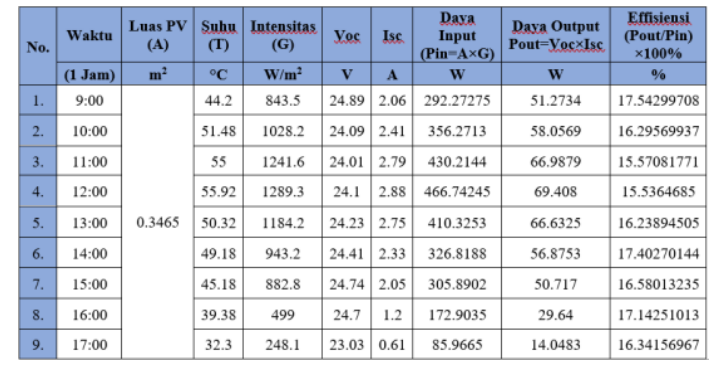

Pengambilan data pada pengujian karakteristik $P V$ ini dilakukan selama 1 hari dimulai dari pukul 09.00 sampai dengan pukul 17.00 dengan jarak waktu pengambilan data tegangan hubung buka ( $\mathrm{V}_{\mathrm{OC}}$ ), arus hubung singkat $\left(\mathrm{I}_{\mathrm{SC}}\right)$ dan Suhu (T) dilakukan setiap 1 jam. [8]

\subsection{Data Karakteristik Photovoltaic}

Pengujian karakteristik $P V$ dilakukakan di aplikasi PSIM dengan bentuk pemodelan ditunjukkan gambar 3 .
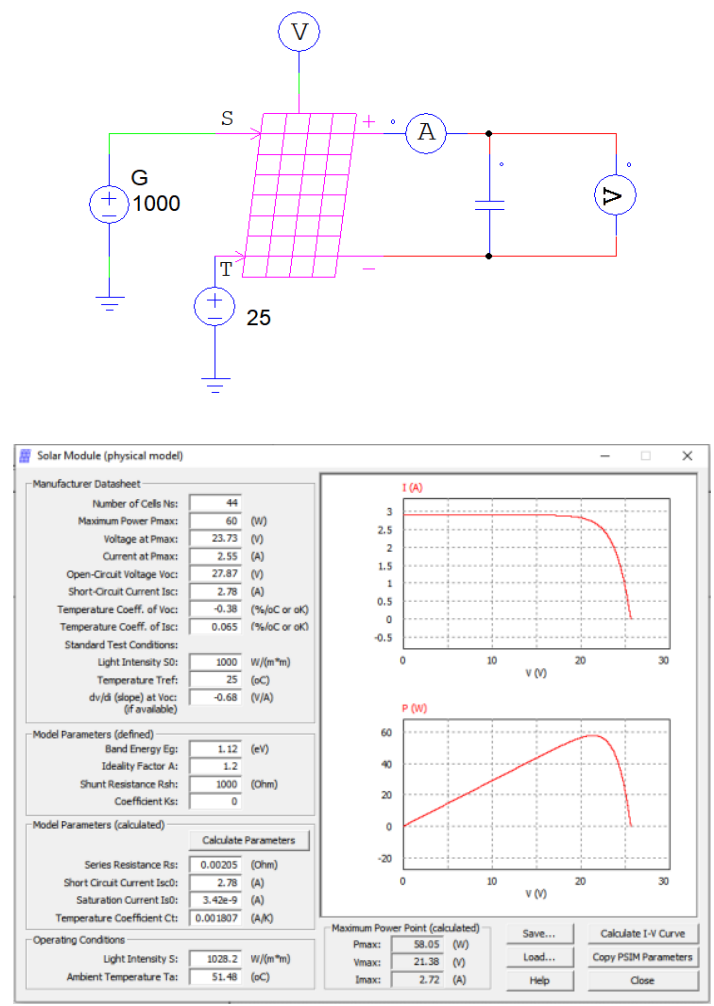

Gambar 3. Pemodelan $P V$ pada PSIM

Dari hasil simulasi berdasarkan data real $P V$ diperoleh kurva karakteristik yang ditunjukkan pada gambar 4 dan gambar 5 .

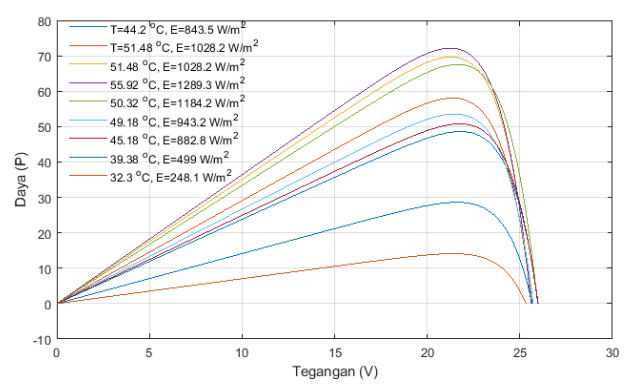

Gambar 4. Kurva daya (p) terhadap tegangan $(\mathrm{V})$ hasil simulasi data real

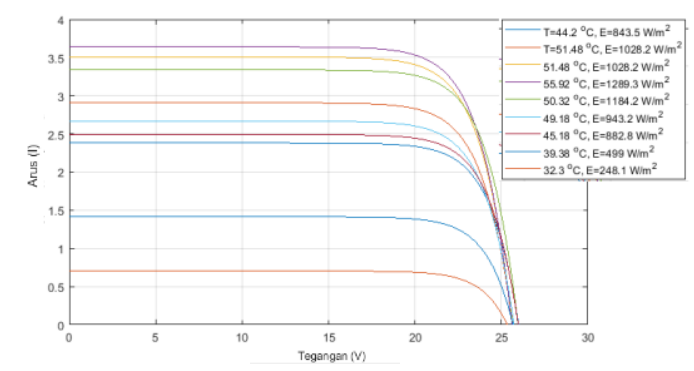


Gambar 5. Kurva arus (I) terhadap tegangan $(\mathrm{V})$ hasil simulasi data real

\subsection{Data Karakteristik Zeta Converter}

pada penelitian ini digunakan sebuah

$D C$-DC ZETA converter. Berikut ini merupakan perhitungan parameter Zeta Converter.

a. Parameter Desain Zeta Converter

$$
\begin{array}{ll}
\mathrm{f} & =45 \mathrm{kHz} \\
\mathrm{V}_{\text {Out }} & =24 \text { Volt } \\
\mathrm{V}_{\text {InMin }} & =21 \text { Volt } \\
\mathrm{V}_{\text {InMax }} & =23 \text { Volt } \\
\Delta \mathrm{I}_{\mathrm{L}} & =10 \% \\
\Delta \mathrm{V}_{\text {Out }} & =1 \% \\
\Delta \mathrm{V}_{\text {In }} & =1 \% \\
\mathrm{I}_{\text {Out }} & =3 \text { Amper }
\end{array}
$$

b. Perhitungan Nilai Komponen Pada Zeta Converter.

1. Duty Cycle (D)

$$
\begin{aligned}
\mathrm{D}_{\text {Max }} & =\frac{\mathrm{V}_{\text {Out }}}{\mathrm{V}_{\text {InMin }}+\mathrm{V}_{\text {Out }}} \\
& =\frac{24 \mathrm{~V}}{21 \mathrm{~V}+24 \mathrm{~V}} \\
& =0.533333 \\
\mathrm{D}_{\text {Min }} & =\frac{\mathrm{V}_{\text {Out }}}{\mathrm{V}_{\text {InMax }}+\mathrm{V}_{\text {Out }}} \\
& =\frac{24 \mathrm{~V}}{23 \mathrm{~V}+24 \mathrm{~V}} \\
& =0.510638
\end{aligned}
$$

2. Arus Input Maksimal ( $\left.\mathrm{I}_{\mathrm{InMax}}\right)$

$$
\begin{aligned}
I_{\text {InMax }} & =I_{\text {Out }} \times \frac{D_{\text {Max }}}{1-D_{\text {Max }}} \\
& =3 \times \frac{0.533333}{1-0.533333} \\
& =3.428571 \mathrm{~A}
\end{aligned}
$$

3. Perkiraan Ripple Arus Pada Induktor

$$
\begin{aligned}
& \text { Saat } \mathrm{V}_{\text {InMin }}\left(\Delta \mathrm{I}_{\mathrm{L}(\mathrm{ppD})}\right) \\
& \begin{aligned}
\Delta \mathrm{I}_{\mathrm{L}(\mathrm{ppD})} & =\Delta \mathrm{I}_{\mathrm{L}} \times \mathrm{I}_{\mathrm{InMax}} \\
& =10 \% \times 3.428571 \\
& =0.342857
\end{aligned}
\end{aligned}
$$

4. Perhitungan Induktor

$$
\begin{aligned}
\mathrm{L} 1 & =\frac{1}{2} \times \frac{\mathrm{V}_{\text {InMin }} \times \mathrm{D}_{\text {Max }}}{\Delta \mathrm{I}_{\mathrm{L}(\mathrm{ppD})} \times \mathrm{f}} \\
& =\frac{21 \times 0.5333333}{0.342857 \times 45000}
\end{aligned}
$$

$$
=362.97 \mu \mathrm{H}
$$

$$
\mathrm{L} 2=\mathrm{L} 1=362.97 \mu \mathrm{H}
$$

5. Perhitungan Kapasitor Output ( $\left.\mathrm{C}_{\mathrm{Out}}\right)$

$$
\begin{aligned}
\mathrm{C}_{\text {Out }} & =\frac{\mathrm{D}_{\text {Min }}}{8 \times \Delta \mathrm{V}_{\text {Out }} \times \mathrm{V}_{\text {Out }} \times f} \\
& =\frac{0.510638}{8 \times 0.01 \times 24 \times 45000} \\
& =5.9102 \mu \mathrm{F}
\end{aligned}
$$

6. Perhitungan Kapasitor Kopling $\left(\mathrm{C}_{\mathrm{C}}\right)$

$$
\mathrm{C}_{\mathrm{C}}=\frac{\mathrm{D}_{\text {Max }} \times \mathrm{I}_{\text {Out }}}{\Delta \mathrm{V}_{\text {In }} \times \mathrm{V}_{\text {Out }} \times \mathrm{f}}=148.148 \mu \mathrm{F}
$$

7. Nilai Tahanan Digunakan (R)

$$
\mathrm{R}=\frac{\mathrm{V}_{\text {Out }}}{\mathrm{I}_{\text {Out }}}=\frac{24 \mathrm{~V}}{3 \mathrm{~A}}=8 \mathrm{Ohm}
$$

Gambar 6. menunjukkan gambar pengujian karakteristik Zeta converter ketika diberikan sumber listrik $D C$ konstan.

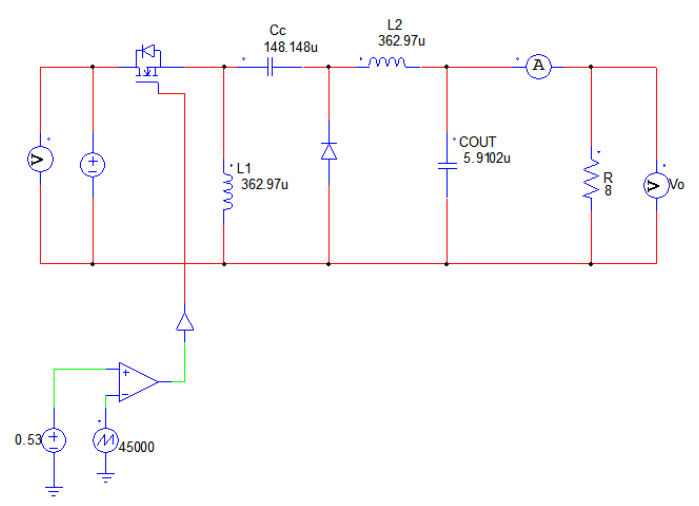

\section{Gambar 6. Pengujian zeta converter dengan sumber $\mathrm{dc}$}

Rangkaian pengujian Zeta converter diatas bertujuan untuk mengamati kondisi tegangan dan arus-nya terhadap waktu. Adapun hasil simulasinya ditunjukkan pada gambar 7.

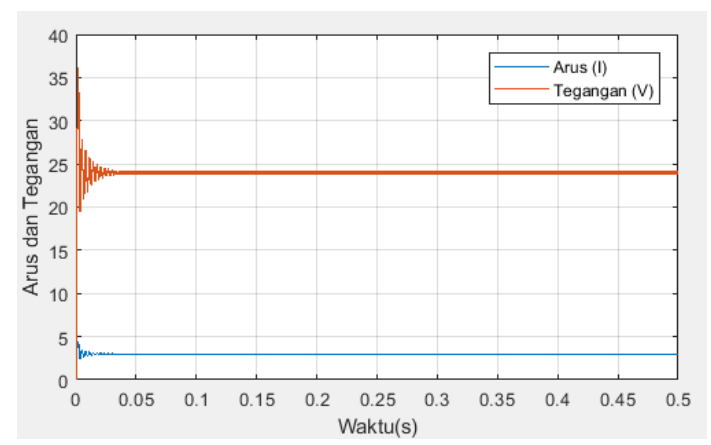




\section{foristek \\ Jurnal Ilmiah Foristek

Gambar 7. Kurva arus dan tegangan terhadap waktu Zeta converter dengan sumber DC

\subsection{Algoritma Hill Climbing}

\section{A. Algoritma Hill Climbing}

Algoritma hill Climbing adalah proses pengujian yang dilakukan dengan menggunakan fungsi heuristik. Pembangkitan keadaan berikutnya sangat tergantung pada feedback dari prosedur pengetesan. Tes yang berupa fungsi heuristik ini akan menunjukkan seberapa baiknya nilai terkaan yang diambil terhadap keadaankeadaan lainnya yang mungkin.

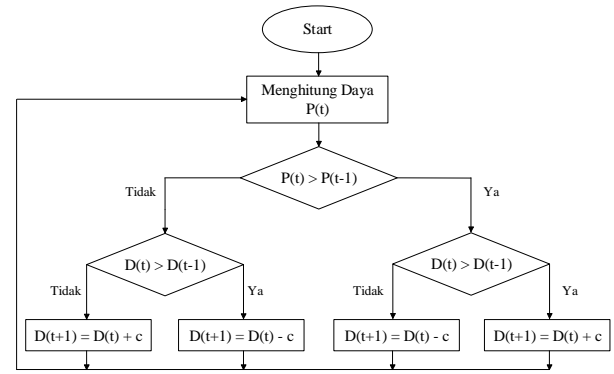

Gambar 8. Flowchart algoritma hill climbing

adapun variabel pencarian awal yang penulis gunakan pada algoritma ini ialah:

$$
\begin{array}{ll}
\mathrm{c} & =0.01 \\
\mathrm{p} 0 & =0 \mathrm{~W} \\
\mathrm{~d} 0 & =0 \\
\text { delay } & =0.0025 \mathrm{~s}
\end{array}
$$

\section{B. Algoritma Hill Climbing}

Algoritma modified hill climbing merupakan ialah metode modifikasi yang dilakukan pada algoritma hill climbing konvensional dengan tujuan mendapatkan variabel output yang lebih baik. [9] Dalam penelitian ini modifikasi yang dilakukan ialah menambahkan variabel $\mathrm{x}$ yang berfungsi sebagai faktor pengali dari nilai konstan c, Hal tersebut bertujuan untuk mengurangi ripple steady state ketika algoritma berhasil mendapatkan daya puncak.

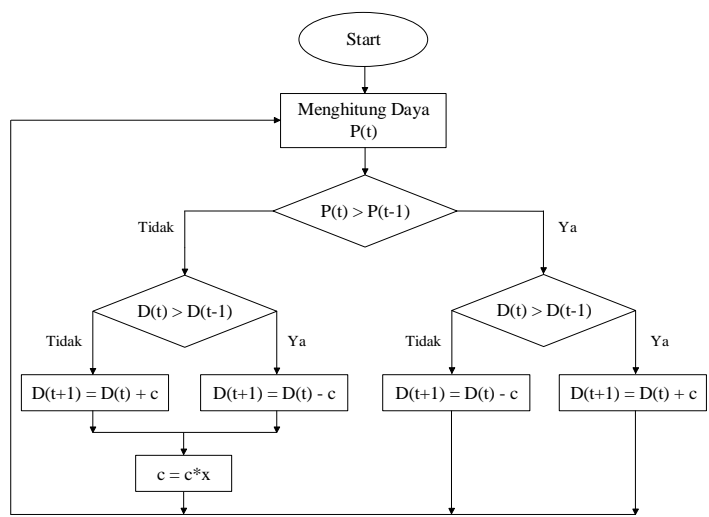

Gambar 8. Flowchart algoritma modified hill climbing

Untuk variabel pencarian awal yang penulis gunakan pada algoritma ini ialah

$$
\begin{array}{ll}
\mathrm{c} & =0.01 \\
\mathrm{x} & =0.9 \\
\mathrm{p} 0 & =0 \mathrm{~W} \\
\mathrm{~d} 0 & =0 \\
\text { delay } & =0.0025 \mathrm{~s}
\end{array}
$$

Gambar 9. merupakan gambar rangkaian pelacakan titik daya maksimum pada $P V$ penelitian ini.

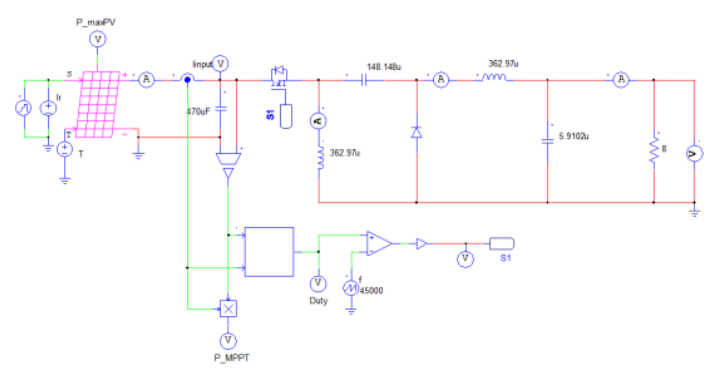

Gambar 9. Rangkaian simulasi Zeta Converter pada pelacakan titik daya maksimum

\subsection{Hasil Running Simulasi}

Setelah melakukan pengujian menggunakan data real yang ada pada Tabel 2, maka berikut ini merupakan hasil tracking 
daya dengan Hill Climbing Method dan Modified Hill Climbing Method.

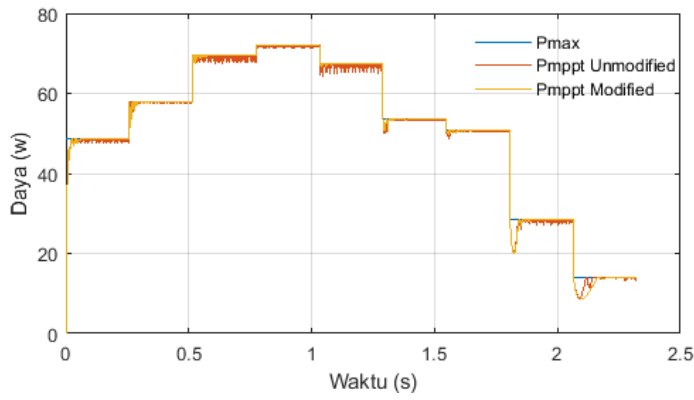

Gambar 10. Grafik pengujian mppt hill climbing dan modified hill climbing dengan variasi data nilai intensitas dan suhu real.

Tabel 3. merupakan perbandingan data hasil tracking daya antara algoritma hill climbing dan modified hill climbing dengan nilai suhu (T) dan intensitas (E) divariasikan berdasarkan data real pengukuran

Tabel 3. Perbandingan hasil pengujian algoritma hill climbing dan modified hill climbing MPPT dengan variasi data nilai intensitas dan suhu real.

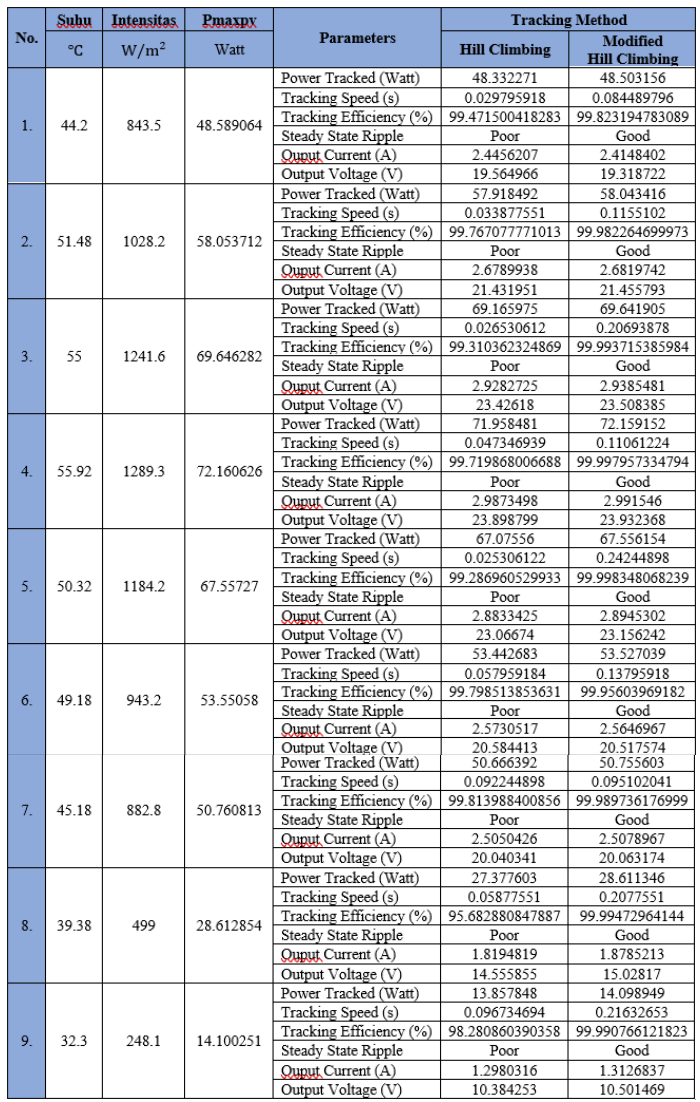

\section{KESIMPULAN}

Berdasarkan hasil penelitian pada perancangan Zeta converter pada pelacakan titik daya maksimum photovoltaic menggunakan algoritma modifikasi hill climbing dapat ditarik kesimpulan antara lain:

1. Pemodelan karakteristik photovoltaic pada penelitian ini dilakukan dengan menggunakan aplikasi PSIM, dengan sampel data tegangan hubung buka $\left(\mathrm{V}_{\mathrm{OC}}\right)$ dan arus hubung singkat ( $\left.\mathrm{I}_{\mathrm{SC}}\right)$ pada variasi Irradiance $(\mathrm{G})$ dan Suhu $(\mathrm{T})$ yang pengambilan datanya dilakukan tiap 1 jam sekali dari pukul 09:00 Wita hingga 17:00 Wita.

2. Parameter Zeta converter dikatakan layak pada suatu sistem MPPT apabila Zeta converter didesain dengan nilai daya output maksimum lebih besar dari nilai daya output maksimum Photovoltaic yang akan ditracking. Pada penelitian ini Zeta converter didesain dengan nilai tegangan output $\left(\mathrm{V}_{\text {Out }}\right.$ ) sebesar 24 Volt dan arus output ( $\mathrm{I}_{\mathrm{Out}}$ ) sebesar 3 Ampere, sehingga diperoleh daya outputnya sebesar 72 Watt yang mana telah lebih besar dari photovoltaic yang digunakan yaitu 60 Watt pada pengujian standard pabrik.

3. Dari hasil pengujian antara algoritma hill climbing dan modified hill climbing diperoleh; data tracking speed pada algoritma hill climbing selalu lebih cepat daripada algoritma modified hill climbing dengan nilai rata-rata 0,046 sekon untuk algoritma hill climbing, dan 0,142 sekon untuk algoritma modified hill climbing. Namun dalam hal efisiensi algoritma modified hill climbing lebih unggul dengan nilai rata-rata $99,969 \%$ dan 99,048 \% untuk algoritma hill climbing. 


\section{DAFTAR PUSTAKA}

[1] D. Ajiatmo and I. Robandi, OPTIMISASI MAXIMUM POWER POINT TRACKER (MPPT) SISTEM PHOTOVOLTAIC (PV) ALGORITMA PADA PENGISIAN BATERAI KENDARAAN LISTRIK BERBASIS FIREFLY ALGORITMA MODIFIKASI, no. June 2016. 2015.

[2] F. Setiawan, M. R. Kirom, and R. F. Iskandar, "Rancang Bangun Maximum Power Point Tracking Menggunakan Buck Converter Dengan Metode Hill Climbing Design of Maximum Power Point Tracking Using Buck Converter With Hill Climbing Method," vol. 3, no. 2, pp. 2019-2024, 2016.

[3] P. P. S. Saputra, "STUDI PERBANDINGAN KONVERTER DC-DC DALAM SISTEM MAXIMUM POWER POINT TRACKING ( MPPT ) SEL SURYA MENGGUNAKAN ALGORITMA PERTURB AND OBSERVE ( $\mathrm{P} \& \mathrm{O}$ )," vol. 1, no. Ic, pp. 237-246, 2018.

[4] E. F. Camacho, Manuel Berenguel, F. R. Rubio, and D. Martínez, Control of SolarEnergy Systems. 2012.

[5] M. Adamek, P. Neumann, and M. Matysek, "Control of solar power systems," Ann. DAAAM Proc. Int. DAAAM Symp., no. Dycops, pp. 233234, 2010.

[6] N. Anani, M. Shahid, O. Al-Kharji, and J. Ponciano, "A CAD package for modeling and simulation of PV arrays under partial shading conditions," 2013, doi: 10.1016/j.egypro.2013.11.040.

[7] M. H. Ahmadi et al., "Solar power technology for electricity generation: A critical review," Energy Sci. Eng., vol. 6, no. 5, pp. 340-361, 2018, doi: 10.1002/ese3.239.

[8] L. A. Hecktheuer, A. Krenzinger, and C. W. M. Prieb, "Methodology for photovoltaic modules characterization and shading effects analysis," Rev. Bras. Ciencias Mec. Brazilian Soc. Mech. Sci., 2002.

[9] A. E. Febtiwiyanti and S. Sidopekso,
"Studi Peningkatan Output Modul Surya dengan menggunakan Reflektor," J. Fis. dan Apl., vol. 6, no. 2, p. 100202, 2010, doi: 10.12962/j24604682.v6i2.919. 